Aletria, Belo Horizonte, v. 30, n. 1, p. 83-94, 2020

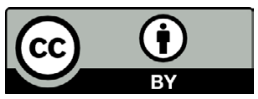

\title{
Silviano Santiago: elogio e crítica a Lévi-Strauss, ou Lévi-Strauss como texto e bom pretexto
}

\section{Silviano Santiago: Praise and Critique of Lévi-Strauss, or Lévi-Strauss as Text and Good Pretext}

\author{
Lilia Katri Moritz Schwarcz \\ Universidade de São Paulo (USP), São Paulo, São Paulo / Brasil \\ lili.schwarcz@gmail.com \\ https://orcid.org/0000-0003-0498-3246
}

Resumo: Este texto analisa o livro de Silviano Santiago, Uma literatura nos trópicos, que completou quarenta anos em 2018, consolidando sua vocação como um "livro de formação". O ensaio procura acompanhar os diversos capítulos da obra e assim destacar o conceito de "entre-lugar", gerado, segundo o próprio autor, a partir do caos experimental-existencial do escritor brasileiro e do seu atravessamento entre o discurso das metrópoles e aquele da produção colonial. O texto objetiva ainda mostrar como, no andamento da obra, a figura de Claude Lévi-Strauss ocupa espaços diversos. Se o etnólogo do primeiro capítulo é o herói de Tristes trópicos, já o antropólogo do último texto de Uma literatura nos trópicos é aquele de Estruturas elementares do parentesco e do amplo projeto intitulado de Mitológicas que, nesse caso, comporta-se como grande "adversário" estrutural.

Palavras-chave: Silviano Santiago; Lévi-Strauss; etnologia, entre-lugar; antropologia; metrópole.

Abstract: This text analyses Silviano Santiago's book A literature in the Tropics, which
has turned its 40th anniversary in 2018, consolidating its vocation as a "formation
book". The essay focuses on tracing several chapters of this work and thus highlights
the concept of "the space in-between", created, according to its own author, from the
Brazilian writer's experimental-existential chaos and from his movement between
the metropolitan discourse and the colonial production. The text aims, moreover, at 
showing, in the course of the work, how the Claude Lévi-Strauss' figure occupies certain spaces. Whereas the ethnologist of the first chapter is the hero of Sad Tropics, the anthropologist of the last text of A literature in the Tropics is that of Elementary structures of kinship and of the vast project entitled Mythologicals which, in this case, behaves as a great structural "adversary".

Keywords: Silviano Santiago; Lévi-Strauss; Ethnology; in-between; Anthropology; metropolis.

O invisivel se torna silêncio.

Silviano Santiago

\section{Introdução: o entre-lugar}

Não sou especialista na vasta obra de Silviano Santiago, tampouco em crítica literária. No entanto, aceitei participar desta coletânea por causa da qualidade do convite e da importância da obra de Silviano, que, entre outros, inspirou toda a minha geração a pensar na importância do conceito de "entre-lugar" no discurso latino-americano.

O conceito de entre-lugar aparece na obra de Silviano Santiago em Uma literatura nos trópicos (1978), que completou quarenta anos em 2018, consolidando sua vocação como um "livro de formação". Mas ele também está presente nos trabalhos sucessivos do autor, como em Vale quanto pesa (1982) e Nas malhas da Letra (1989), tendo um lugar estabelecido, nos dias de hoje, na assim chamada área de Estudos Culturais, nos Estados Unidos, e aqui no Brasil em disciplinas variadas que partem da Literatura, mas chegam à Sociologia e à Antropologia.

Segundo o próprio Silviano, "o conceito de entre-lugar foi gerado a partir do caos experimental-existencial do escritor brasileiro" $\mathrm{e}$ do seu atravessamento entre o discurso das metrópoles e aquele da produção colonial. Retirando-o de um lugar estático e estrito, o crítico apresenta um termo cuja especificidade é estar sempre em contínuo processo.

Por outro lado, seguindo a definição de Jacques Derrida (1995), Silviano trabalha com o jogo semântico que o filósofo francês realiza em torno do termo différance. ${ }^{2}$ Diferente da forma que ganha

${ }^{1}$ Cf. Skrepetz, 2017.

${ }^{2}$ Para um desenvolvimento do conceito, cf. Skrepetz, 2017. 
no Brasil, no contexto linguístico francês a palavra guarda o sentido mais literal, de diferença, mas também de diferimento e repetição. Tal oscilação vocabular é que permite tomar o conceito não apenas como "dependência" - dependência de um discurso alheio -, mas, igualmente, como a sua subversão.

Différance, nas palavras de Silviano Santiago, remete a "silêncio e segredo", numa concepção não coincidente mas espelhada à de Derrida (2004). Por isso mesmo, talvez se possa dizer que o entre-lugar é um conceito que não "fixa". Ele opera em processo e assim vai criando outras possibilidades e gerando novas derivações. Nas palavras de Silviano "desloca-se e difere-se". Por isso, também, o entre-lugar representa sempre o deslocamento, a deformação e a diferença. Não há nada nele que seja derradeiro. Aliás, o conceito, tal qual aparece na obra do crítico brasileiro propõe antes um diálogo com Derrida, filósofo que também alertou para o perigo de transformar esse "entre" em "outro lugar": outra essência ou natureza. ${ }^{3}$ É justamente no afastamento da verdade que reside a verdade: no plano daquilo que não se decide de forma derradeira ou definitiva.

Tomado nesses termos, o conceito de entre-lugar vertebra a partir de várias perspectivas. Ou seja, é acionado no plano estético da cultura e da literatura latino-americana, mas também no seu plano ético. O entre-lugar é, pois, um termo cheio de contaminações, e que, na trilha deixada pelo filósofo francês (mas partindo do lugar do pensamento "dito" colonizado), explora a ideia de desconstrução e de diferimento. Isto é, a maneira como a literatura brasileira "importa" a forma europeia, mas a "traduz" diferindo-se dela.

É essa contínua e constante capacidade de deslocamento (ou de des-loucar) que se apresenta como ponto inicial para a obra desenvolvida pelo ensaísta brasileiro. O entre-lugar não se desloca; "desloca-se a si mesmo". ${ }^{4}$ Dessa maneira, de forma muito precoce e original, Santiago introduz o discurso decolonial nos trópicos, politizando a crítica literária, ao mesmo tempo que a qualificando.

A obra e o conceito desenvolvidos por Silviano tiveram tal impacto que escaparam das fronteiras da literatura para ganhar outros

${ }^{3}$ Cf. Skrepetz, 2017.

${ }^{4}$ Cf. Skrepetz, 2017. 
espaços analíticos. ${ }^{5}$ Não pretendo aqui tratar da imensa e importante obra de Silviano Santiago como um todo. Minha intenção é limitar-me à análise do livro Uma literatura nos trópicos e, muito especialmente, a dois capítulos que dialogam com a antropologia; disciplina que eu (talvez) represente, no conjunto de artigos que compõem esta coletânea.

Refiro-me ao primeiro capítulo da obra, "O entre-lugar do discurso latino-americano", e ao último capítulo do livro (o décimo-primeiro), chamado "Análise e interpretação".

Interessante pensar que se no primeiro capítulo Silviano sinaliza para um namoro com a etnologia, já no segundo o crítico dá uma "mordida" no estruturalismo de Lévi-Strauss e quase que "rompe" com ele. Não existe, como certeza, um "viveram felizes para sempre".

\section{O entre-lugar no discurso latino-americano e o diálogo com a etnologia}

Não por coincidência, o primeiro capítulo de Uma literatura nos trópicos começa analisando o capítulo XXXI dos Ensaios, de Montaigne (2017), quando o autor trata dos canibais no Novo Mundo. Silviano usa da referência - "Não sei que bárbaro são estes [...] mas ou eles o são ou nós o somos" - para refletir sobre o "lugar" que ocupa o discurso latinoamericano no confronto com o europeu.

$\mathrm{Na}$ verdade, Silviano Santiago retira de Montaigne a metáfora fundamental para pensar sobre "nós, antropófagos da América do Sul" (SANTIAGO, 1978, p. 12), mais precisamente dos autores brasileiros, e para assim marcar o conflito entre civilizado e bárbaro, entre colonialista e colonizado, entre Grécia e Roma, entre a Europa e o Novo Mundo.

\footnotetext{
${ }^{5}$ Numa nota mais pessoal, gostaria de lembrar que, por todos os motivos acima discriminados, acabei por "emprestar" do crítico a noção de entre-lugar para pensar a literatura de Lima Barreto. O conceito e a metodologia explorados por Silviano Santigo serviram como aporte para refletir sobre uma certa forma de operar que não poderia ser limitada à ideia de influência ou de continuidade, sendo melhor pensá-la como "dobra". Ou seja, quanto mais buscava se inspirar na literatura europeia, mais deixava clara a sua inevitável diferença. Também a obra de Homi Bhabha (2000) me ajudou a encontrar nos textos do escritor de Todos os Santos um projeto de alguma maneira coadunado aos escritos que, nos anos 1980, ganharam o conceito de pós-coloniais. Bhabha encontra no "entre-lugar" a chave para compreender os processos de ressignificação cultural criados pelas antigas metrópoles.
} 
Essas são polaridades que só se constituem "em relação" $e$ "na relação", e o crítico explora justamente $o$ lugar da relação; o "entre".

Afinal, o rei Pirro havia se subestimado à força dos "bárbaros", e, apesar do desequilíbrio econômico e militar, não conseguiu vencer o povo "inferior". O que Pirro, rei do Epiro e da Macedônia (318 a.C. a 272 a.C.), não notou é que ele estava diante de uma outra linguagem da guerra. Tratava-se de uma outra arte militar que permitia questionar o conceito de superioridade e, de certa forma, inverter valores estabelecidos.

É nesse sentido, também, que o etnólogo Claude Lévi-Strauss, em Tristes trópicos (1996) menciona a "ignorância mútua" que imperou no contato entre colonizados e colonizadores. Afinal, enquanto os brancos achavam que os índios eram animais, esses achavam que os europeus eram deuses. Mas o desconhecimento, de parte a parte, não teve a capacidade de apagar valores ou hierarquias previamente estabelecidos. Tanto que, da parte dos colonizados, o processo implicou a "perda de seus idiomas e de suas línguas originais" (SANTIAGO, 1978, p. 13), no fim do pluralismo religioso; grandes tentáculos do poder colonial ao impor sua hegemonia.

O viajante português Gândavo (2008), por exemplo, ainda no século XVI, definiu os povos americanos pela "falta": eram "povos sem fé, sem lei e sem rei". O certo é que, como diz o ditado, Narciso acha feio o que não é espelho e os habitantes do Novo Mundo seriam caracterizados pelo sentido da "ausência". Na falta de muitos (e da própria ideia de "complexidade", os americanos teriam "um só Deus, um só Rei, uma só Língua", conclui Silviano Santiago. É assim que a América se transforma, nas palavras do crítico, em cópia, em simulacro, mais ou menos semelhante ao original; com sua origem sendo, sistematicamente, apagada pelos conquistadores (SANTIAGO, 1978, p. 14).

Tal processo implica também dissimular marcas de origem. E, sendo assim, os povos e as cidades do Novo Mundo tornam-se tautologicamente "novos", com as designações sublinhando sua "novidade" e "juventude": Nova Espanha, Nova Inglaterra, Nova Friburgo, Nouvelle France e assim vamos.

O problema é que, diferentemente das designações e das conotações mais contemporâneas, "novo", nesse contexto de colonização, significa "fora de moda". Conforme explica Lévi-Strauss (1996): "Os trópicos são menos exóticos do que fora de moda" (SANTIAGO, 1978, p. 14). E Silviano Santiago assinala como no "neocolonialismo" uma nova 
máscara aterroriza os países do Terceiro Mundo, agora no século XX (ou XXI). O que se percebe no contexto atual é a exportação de objetos fora de moda para as sociedades neocolonialistas, que viram, dessa maneira, centros de consumo de produtos já excessivos nos mercados centrais.

O renascimento colonialista também engendra uma nova sociedade: a dos mestiços. Essa, porém, também percorre um caminho inverso ao dos colonos. Se a América Latina não pode mais fechar suas portas às invasões estrangeiras, também não pode reencontrar sua condição de "paraíso" projetivo, de isolamento e de inocência.

Para o imperialismo cultural, a saída seria o "silêncio" que tem o poder de apenas apertar os laços com o conquistador. Já falar e escrever transformam-se em atos de resistência; de ir "contra". E é nesse sentido que, no primeiro capítulo, Silviano Santiago faz um elogio rasgado à etnologia da época da concepção e publicação do primeiro ensaio de Uma literatura nos trópicos. Afinal, seriam os etnólogos os responsáveis pela desmistificação do discurso da História, dissipando o véu do imperialismo cultural. ${ }^{6}$ São eles que teriam, ainda, ressuscitado a beleza do objeto artístico da cultura desmantelada pelo colonizador.

Segundo Silviano, ao invés de tomar um texto como mera "influência", como se a verdade de uma obra residisse apenas na dívida e na imitação que carrega consigo, a etnologia teria explorado, de maneira precoce, a existência de "outros regimes de historicidade", outras histórias, diferentes daquela ocidental, que se quer "universal". ?

É assim, fazendo bom uso também das lentes da etnologia, que o crítico literário restitui o imaginário do espaço do neocolonialismo. Esse espaço teria uma lógica própria, pois uma escritura se escreve sobre a escritura, uma obra sobre a obra (SANTIAGO, 1978, p. 14).

Nesse contexto heurístico, a própria "tradução" do significante avança no sentido de se criar um novo significado. Ao invés da "cópia", temos um texto que afronta o primeiro, e muitas vezes o nega. O certo é que algo novo se produz quando privilegiamos a existência de um texto dentro de um texto. Algo que assinala a ruptura entre o modelo e a sua

\footnotetext{
${ }^{6}$ Nessa etnologia de época eu inseriria também os livros que Pierre Clastres publicou à época, como $A$ sociedade contra o Estado (1982).

${ }^{7}$ Vale a pena, nesse sentido, ler o texto de Claude Lefort, Formas da história (1979), publicado também nesse contexto.
} 
cópia, com o "invisível tornando-se silêncio" e o escritor latino-americano virando um devorador de livros. Um antropófago de livros.

Fico me perguntando, nesse sentido, e entre parênteses, se Machado, de Silviano Santiago, publicado em 2016, e que consagraria o crítico, definitivamente, como escritor de ficção, não seria como o Pierre Menard, autor de El Quijote de autoria de Jorge Luis Borges (1944). Ou então um parente próximo da literatura de Juan José Saer, particularmente El antenado (1983), quando o narrador é também um "comedor". Fecho parênteses.

De toda maneira, nesse primeiro capítulo, que abre Uma literatura nos trópicos, Silviano Santiago dialoga de forma orgânica com o modelo do etnólogo que acha beleza no que era, até então, silêncio.

No entanto, quando chegamos ao capítulo 11 , justamente o último, o que parecia certeza vira dúvida; o que funcionava como exemplo alterativo se transforma em prática etnocêntrica e colonial.

Nesse caso, a operação é em tudo oposta, com Silviano endereçando sua crítica ao estruturalismo de Lévi-Strauss. Ou seja, se o autor, de alguma maneira, se filia ao modelo de Roland Barthes, ${ }^{8}$ apontando na metodologia desse crítico três formas de "entre-lugares" - a desmontagem, o arranjo e o simulacro -, já a teoria de Lévi-Strauss, que diz utilizar um método que se assemelha ao do bricoleur - aquele do antigo relojoeiro que traz consigo as peças e partir daí cria um projeto e que está presente em O pensamento selvagem (1989)-, é agora profundamente questionado.

O etnólogo seria, então, entendido como o bricoleur de um universo tão fechado como vazio de significado (na acepção da linguística estrutural de Saussure, 2004). Já o estruturalismo transforma-se em um método que busca apreender o "todo" e assim falha ao ser incapaz de ver particularidades. Falha também ao despolitizar a análise, chamando de "universal" uma linguagem universal do parentesco, por exemplo, o que é de fato europeu.

Como se pode notar, Silviano deixa dessa vez "a noiva", com quem até então namorava, no "altar", e envereda pela crítica ao estruturalismo desenvolvida por Gilles Deleuze e Jacques Derrida, que denunciavam,

\footnotetext{
${ }^{8}$ Cf., por exemplo, Roland Barthes, Mitologias (2002), obra originalmente publicada em 1957.
} 
nesse momento, o que seria a "leitura opaca" e "sem especificidades", do estruturalismo.

Segundo nosso crítico, a análise estrutural em antropologia não teria a preocupação de enxergar e compreender a "diferença". Aliás, não existiria no estruturalismo "diferença" ou diálogo "entre textos"; tampouco intertextualidade. Segundo essa leitura crítica, o estruturalismo não questionaria a maneira de pensar e ler ocidental, pois tal atitude implicaria, também, questionar "as certezas do pensamento centrado no Ocidente" (SANTIAGO, 1978, p. 210).

É nesse momento que Silviano retoma o significado mais eminentemente político do conceito de entre-lugar, para mostrar como ele coloca em questão o lugar do sujeito de conhecimento - o autor - e o próprio processo necessário de transgressão de uma cultura dominante. Para nosso crítico, a afirmação, a negação e a contradição se afirmam por meio da diferença e não pela reiteração ou pela síntese, como pretendia realizar o Lévi-Strauss de As estruturas elementares do parentesco, editado pela primeira vez em 1949.

A crítica é forte, e vem acompanhada de Derrida, para quem a ideia de cultura e de natureza, expressa na teoria estrutural de LéviStrauss, padeceria de etnocentrismo. Escaparia ao etnólogo o momento de significação anterior à diferenciação. Falta-lhe olhar "para a margem"; para "a dupla marca, da leitura dupla, da escritura dupla" (SANTIAGO, 1978, p. 211).

O problema desaguaria na questão da interpretação. Lévi-Strauss não estaria preocupado em desconstruir o discurso da "metafísica ocidental" que se quer, justamente, universal. A saída advogada por Silviano Santiago seria usar, juntos, os vocabulários da diferença e da violência para assim criar uma "interpretação polissêmica" que buscasse não a "totalidade" indistinta, mas antes o "incomplemento", assim descentrando a estrutura. A busca não seria por um significado central, originário e transcendental, mas pela própria diferença, como interpretação polissêmica.

Por outro lado, ao descentrar a estrutura de um significado único, originário e transcendental, Silviano busca pelo "diferimento", como quer Jacques Derrida. Emancipar a linguagem faria parte, pois, do entre-lugar da literatura latino-americano e da lógica do pensamento colonial, que já nasce híbrido de sentidos, e por isso mesmo procura sempre por sua ambivalência constitutiva. 


\section{O fim e o começo}

Interessante pensar como, nesse seu livro clássico, uma vez que ele ainda se mantém muito atual mesmo passados quarenta longos anos, Silviano Santiago seleciona a figura de Claude Lévi-Strauss como uma referência central. No entanto, se o etnólogo do primeiro capítulo é o herói de Tristes trópicos, já o antropólogo do último texto de Uma literatura nos trópicos é aquele de Estruturas elementares do parentesco e do amplo projeto intitulado de Mitológicas que nesse caso é o grande "adversário estrutural".

Não é o caso de desempatar essa partida, muito menos de optar por um dos livros de Lévi-Strauss ou mesmo apenas contrapor um pensador a outro. Mais interessante é retomar, por outro ângulo, o debate tão produtivo que vem se estabelecendo na área de Pensamento Social, que reiteradamente colocou em tensão modelos historicistas e aqueles mais formalistas. Nesse sentido, os dois livros selecionados por Silviano, Tristes trópicos e Estruturas elementares do parentesco, ou até mesmo as Mitológicas, a despeito de serem de autoria de um mesmo autor, guardam momentos diferentes na carreira do etnólogo. Esse é o "diferimento", para evocarmos um termo de nosso crítico literário, de Lévi-Strauss.

O primeiro corresponde a um primeiro experimento do etnólogo, publicado anos depois de sua escrita original, e sem a preocupação de constituir uma teoria para a etnologia ou, até mesmo, para a humanidade. O livro que Silviano Santiago pinça, no primeiro capítulo, é, por assim dizer, mais pautado no testemunho que é sempre particular. Já o segundo faz parte da arquitetura de um projeto que se pretende universal na sua forma, não no seu conteúdo. Ou seja, as estruturas seriam como significantes, destituídas de significado; já as culturas - o significado sempre variadas.

Talvez valeria indagar quais são as condições do escritor, ou, melhor dizendo, quais as condições para a própria narrativa. E o exemplo do etnólogo Claude Lévi-Strauss, em seu livro Tristes trópicos, é particularmente significativo. Significativo por conta do registro de memória que ele testemunha.

A história deste livro também é importante para o paralelo que aqui pretendo realizar. Contam os biógrafos de Lévi-Strauss, que em 1954, a editora francesa Plon teria pedido a Jean Malaurie, um jovem especialista em populações esquimós e lapônias, que idealizasse uma 
coleção etnográfica intitulada "Terra Humana". Ele então convidou Claude Lévi-Strauss, na época um jovem pesquisador. Costuma-se dizer que que em apenas quatro meses o então aprendiz de etnógrafo entregou seu manuscrito - apesar de não sabermos se tal datação não faz parte, ela própria, da mitologia pessoal de Lévi-Strauss, que sempre disse que os livros "se escrevem nele".

Lévi-Strauss deveria entregar um livro baseado na viagem que fizera ao Brasil, nos anos 1930. Ocorre que, naquela ocasião, ele havia recém-iniciado um romance, do qual aproveitou apenas o título: "Tristes trópicos". Nesse livro, ao mesmo tempo poético e de caráter testemunhal, o antropólogo se mostra evidentemente dividido; tanto que se dá a liberdade de escrever uma obra "fora da curva", da sua curva, empregando a primeira pessoa do singular, e defendendo uma espécie de "eu odioso"; aquele do etnólogo que detesta tudo o que vislumbra, que vai de encontro à decadência ao invés de reconhecer a potência de outra civilização. ${ }^{9}$

Foi em 1952 que Claude Lévi-Strauss deu início, com Raça e história (1952), a seu projeto mais ambicioso que implicaria a possibilidade de pensar em outras histórias e sua relação com novas historicidades, não pautadas no modelo evolutivo e contínuo ocidental. "História" corresponderia, então, à versão ocidental (em que a diacronia é critério fundamental) e "historicidade", justamente, às outras e várias formas de narrar a história.

A partir daí ele enveredaria num projeto gigantesco que começava com Estruturas elementares do parentesco e chegava em Mitológicas. Foram 24 anos de estudos, de 1946 a 1971, cuja proposta era chegar aos elementos mais mínimos, aos átomos de parentesco e aos mitemas.

Não há espaço para refazer aqui a teoria criada por Claude LéviStrauss, nesse contexto. Arrisco dizer, porém, que esses são caminhos e veredas distintos e que não há melhor trilha a seguir. Não por acaso, as datas das obras do etnólogo correspondem, grosso modo, aos anos de publicação dos próprios capítulos dos ensaios que compõem Uma literatura nos trópicos.

Silviano tem razão. O lugar do escritor sempre borra fronteiras e por isso mesmo se justifica o entre-lugar. Afinal, escrever é sempre o início de algo que não tem exatamente um fim; até porque vai se borrando no caminho.

${ }^{9}$ Cf. Castro, 2009. 


\section{Referências}

BARTHES, Roland. Mitologias. São Paulo: Difel, 2002.

BHABHA, Homi. O local da cultura. Tradução de Eliana Lourenço de Lima Reis, Gláucia Renate Gonçalves e Myriam Ávila. Belo Horizonte: Editora UFMG: 2000.

BORGES, Jorge Luis. Pierre Menard, autor do Quixote. In: BORGES, Jorge Luis. Fiç̧ões. Buenos Aires: Ediciones Sur, 1944.

CASTRO, Eri Santos. "Tristes Trópicos": uma das principais elaborações do século XX. Blog Eri Castro, [s.l.], 4 nov. 2009. Disponível em: $\mathrm{http}: / /$ erisantoscastro.blogspot.com/2009/11/tristes-tropicos-uma-dasprincipais.html]. Acesso em: 10 jan. 2020.

CLASTRES, Pierre. A sociedade contra o Estado. Tradução de Theo Santiago. Rio de Janeiro: Francisco Alves, 1982.

DERRIDA, Jacques. A escritura e a diferença. Tradução de Maria Beatriz Marques Nizza da Silva, Penola de Carvalho e Pedro Leite Lopes. São Paulo: Perspectiva, 1995.

DERRIDA, Jacques. Gramatologia. Tradução de Miriam Schnaiderman e Renato Janine Ribeiro. São Paulo: Perspectiva, 2004.

GÂNDAVO, Pedro de Magalhães. Tratado da Terra do Brasil. Brasília: Senado Federal, Conselho Editorial, 2008. [Manuscrito original de 1576 pertence à Biblioteca do Porto, Portugal].

LEFORT, Claude. Formas da história: Ensaios de antropologia política. São Paulo: Brasiliense, 1979.

LÉVI-STRAUSS, Claude. O pensamento selvagem. Tradução de Tania Pellegrini. Campinas, SP: Papirus, 1989.

LÉVI-STRAUSS, Claude. Raça e história. Tradução de Inácio Canelas. Lisboa: Editorial Presença, 1952.

LÉVI-STRAUSS, Claude. Tristes trópicos. Tradução de Rosa Freire D’Aguiar. São Paulo: Companhia das Letras, 1996.

MONTAIGNE, Michel de. Os Ensaios. Tradução de Rosa Freire D’Aguiar São Paulo: Penguin \& Companhia das Letras, 2017.

SAER, Juan José. El antenado. Buenos Aires, México: Folios, 1983. 
SANTIAGO, Silviano. Nas malhas da letra. São Paulo: Companhia das Letras, 1989.

SANTIAGO, Silviano. Uma literatura nos trópicos. São Paulo: Perspectiva, 1978.

SANTIAGO, Silviano. Vale quanto pesa. São Paulo: Paz e Terra, 1982.

SAUSSURE, Ferdinand de. Escritos de linguística geral. São Paulo: Cultrix, 2004.

SKREPETZ, Inês. Silviano Santiago e o entre-lugar na Literatura. Texto adaptado por Caroline Svitras. Conhecimento Prático Literatura, [s. l.], 03 out. 2017. Disponível em: https://conhecimentoliteratura.com.br/ silviano-santiago-e-o-entre-lugar-na-literatura/. Acesso em: 10 jan. 2020.

Recebido em: 25 de setembro de 2019. Aprovado em: 27 de dezembro de 2019. 